\title{
Water restriction impact on surface hardness and soil volumetric water content on recreational sports fields
}

Kuo-Hsien Chang, Jacqueline E. Powers, and Eric Lyons

This is the peer reviewed version of the article, which has been published in final form at https://doi.org/10.2134/itsri2016.09.0832. This article may be used for non-commercial purposes in accordance with Wiley Terms and Conditions for Use of Self-Archived Versions

Suggested Citation: Chang, K.-H., Powers, J.E. and Lyons, E. (2017), Water Restriction Impact on Surface Hardness and Soil Volumetric Water Content on Recreational Sports Fields. Int. Turfgrass Soc. res. j., 13: 614-618.

https://doi.org/10.2134/itsri2016.09.0832 


\section{Water restriction impact on surface hardness and soil volumetric water content on recreational sports fields}

\section{Kuo-Hsien Chang, Jacqueline E. Powers, and Eric Lyons}

Affiliation: Department of Plant Agriculture, University of Guelph, Guelph, Ontario, Canada N1G 2W1.

Abstract: Water-use restrictions during the summer of 2016 in Guelph, ON, Canada, prevented the irrigation of natural turf soccer fields and provided a unique opportunity to study the effects on soil volumetric water content and surface hardness on actively used youth soccer fields. Soil volumetric water content and surface hardness were tested on a weekly basis from July through September 2016. Areas of the turf that became brown were compared with the areas that remained green. Surface hardness within areas of brown turfgrass cover frequently exceeded $100 \mathrm{~g}$ (level of concern for player safety) even though soil volumetric water content was similar between the areas of green and brown turfgrass cover. Therefore, irrigation of sports fields during times of drought is recommended to preserve the cushioning effect of green turfgrass cover.

Abbreviations: ANCOVA, analysis of covariance; CIST, Clegg impact soil tester; VWC, volumetric water content.

Playing field conditions result from a number of contributing variables that include soil moisture, surface hardness, grass type, grass cover and health, and the evenness of the playing field (Canaway and Baker, 1993; Orchard, 2002). The condition and quality of natural turf sports fields are influenced by seasonal and day-to-day weather variations, as well as maintenance and wear (Baker, 1991). Surface hardness is negatively correlated with soil moisture on game and practice fields (Rogers et al., 1988; Rogers and Waddington, 1990; McNitt and Landschoot, 2001). The surface hardness of natural turf has been identified as one of the key components of turf to be associated with injury incidence (Rogers and Waddington, 1990; Baker and Canaway, 1993; Orchard, 2002). Players experience greater forces of impact throughout the foot 
when running on harder surfaces (Low and Dixon, 2014). Over $20 \%$ of concussions suffered by high school athletes are the result of impact with the playing field (Gessel et al., 2007). When noncontact injury in football is attributed to ground conditions, it is mainly due to either excessive rotational traction or excessive surface hardness (Rogers et al., 1988). Researchers have linked a higher incidence of anterior cruciate ligament (ACL) injury to greater surface hardness on natural turf (Orchard, 2001; Chivers et al., 2005). It was because of this perceived link between greater surface hardness and risk for player injury that sports fields were closed in Melbourne in 2016 due to a drought that killed off ground cover and resulted in excessive field hardness (Ford and Twomey, 2016).

However, a recent comprehensive literature review of articles linking any injury to field conditions found that of the few that measured surface hardness, none were able to show a direct correlation between field hardness and an increased risk of injury (Petrass and Twomey, 2013; Rennie et al., 2016). This was theorized to be due to the subjective means by which field hardness was determined. In fact, when comparing subjective and objective assessments of field hardness, Twomey et al. (2014) found that less than half of the assessments were in agreement with one another.

The Clegg impact soil tester (CIST) or Clegg hammer is a recognized tool for measuring surface hardness on natural turf (ASTM, 2010). The CIST has the advantage of being the most reliable device for the assessment of hardness amongst novice and experienced testers (Twomey et al., 2011). The CIST uses a weighted missile (either 0.5 or $2.25 \mathrm{~kg}$ ) equipped with an accelerometer dropped down a guide tube from a specified height to measure peak deceleration generating gravity values (g) (also referred to as "Gmax" in the literature) as an indication of surface hardness. Greater readings equate to a greater surface hardness. On the basis of hardness values obtained from the CIST with the 0.5-kg missile, Canaway et al. (1990) suggested a preferred upper limit of $80 \mathrm{~g}$ for sports fields.

Player's perception of surface hardness was found to be positively correlated with the peak deceleration values using the $0.5-\mathrm{kg}$ CIST hammer dropped from $0.55 \mathrm{~m}$ (Canaway et al., 1990).When using the $2.25-\mathrm{kg}$ missile dropped from $0.45 \mathrm{~m}$, surface 
hardness $>120 \mathrm{~g}$ was considered to be high and a greater risk of causing player injury (Chivers and Aldous, 2004). These limits were based on player perception, and therefore any relevance to potential injury is uncertain. Unfortunately, there is no hard data correlating injury to a CIST threshold for surface hardness of natural turf.

Current ASTM (2010) guidelines for surface hardness propose that impacts $>100 \mathrm{~g}$ may pose a safety hazard. Players' perceptions of surface hardness suggested an upper limit of $80 \mathrm{~g}$ (Canaway et al., 1990).

Lower surface hardness typically is observed where turf is not exposed to wear and turf cover is good compared with areas where turf cover is worn (Rogers et al., 1988; Sifers and Beard, 1997; McNitt and Landschoot, 2001). There is an inverse correlation between soil volumetric water content (VWC) and surface hardness (Rogers et al., 1988; Rogers and Waddington, 1990; McNitt and Landschoot, 2001). The extent to which soil VWC influences surface hardness is related to soil texture. On finer-textured soil, soil VWC has a greater effect on surface hardness than it does on sand profiles (Rogers et al., 1988; Baker, 1991).

This relationship between soil WWC on surface hardness means that player safety on natural turfgrass sports fields is potentially vulnerable to environmental conditions. Water restrictions in Guelph, ON (City of Guelph, 2016), prohibited all nonessential water use on all recreational fields including two soccer fields at the Guelph Turfgrass Institute (GTI). These fields provided a unique opportunity to study the effects of drought on soil VWC and surface hardness of an actively used playing field and determine whether field conditions become hard enough to be considered an injury risk for players during prolonged drying.

\section{Materials and methods}

\section{Field Sites}

Two soccer fields ( $A$ and $B)$ at the Guelph Turfgrass Ontario $\left(43^{\circ} 33^{\prime} 00.000^{\prime \prime} \mathrm{N}\right.$, $80^{\circ} 13^{\prime} 00.000$ " W; $325.00 \mathrm{~m}$ asl) were used in this study. The soil was a sandy loam planted to Kentucky bluegrass (Poa pratensis L.) and overseeded with perennial ryegrass (Lolium perenne L.) and supina bluegrass (Poa supina Schrad.). In 2016, the fields were fertilized for with $0.5 \mathrm{~kg} \mathrm{~N} 100 \mathrm{~m}^{-2}$ using a 25-4-10 $\left(\mathrm{N}-\mathrm{P}_{2} \mathrm{O}_{5}-\mathrm{K}_{2} \mathrm{O}\right)$ fertilizer 
on 11 May and core aerated on 27 May. No fungicides, herbicides, or insecticides were used (provincial ban on sports fields since 2009). The fields were mowed on average every $5 \mathrm{~d}$ to a height of $38 \mathrm{~mm}$ using a belly mount rotary mower (Ventrac).

\section{Soil VWC and surface hardness}

As water restrictions persisted, patches of brown turfgrass appeared intermingled amongst green turfgrass. The original intent to gather data on surface hardness as a consequence of drying soil conditions was expanded to further address whether the loss in green color in the turfgrass corresponded with a change in surface hardness.

Soil VWC and surface hardness were collected approximately every week from 13 July through 2 Sept. 2016 at nine locations of both green and brown turfgrass within Fields A and $B$ (Fig. 1). Green and brown turfgrass were intermingled throughout the fields such that paired measurements of green and brown turfgrass areas were within $0.5 \mathrm{~m}$ for a total of 18 measurements. Care was taken to measure approximately the same locations on each date of data collection.

Soil VWC was measured to $60-\mathrm{mm}$ depth using the Theta Probe type ML2x coupled with the readout and storage device Moisture Meter HH2 (Delta-T Devices). The soil probe has four rods, with three rods arranged around a central rod, creating a defined cylindrical zone of 60-mm depth $\times 30-\mathrm{mm}$ width. The probe was pressed firmly into the soil, and four measurements were recorded and averaged for each data point.

Surface hardness was measured using the CIST (Lafayette Instrument Company) equipped with a $0.5-\mathrm{kg}$ hammer dropped from a height of $0.55 \mathrm{~m}$ at the same 18 sites as the soil VWC measurements for each sampling date. Readings were taken as the average of four successive drops of the hammer in the same spot. Although some reports have used the $2.25 \mathrm{~kg}$ Clegg hammer dropped from a height of $0.45 \mathrm{~m}$ to determine surface hardness, the $0.5-\mathrm{kg}$ Clegg hammer was the device available. Along with Canaway et al. (1990), other researchers have used the 0.5-kg missile dropped from a height of $0.55 \mathrm{~m}$ to measure surface hardness as it relates to foot impact and for sports field construction, respectively (Dixon et al., 2008; Hejduk et al., 2012). Further, the measurements with the $0.5-$ and $2.25-\mathrm{kg}$ hammers are strongly correlated (Rogers, 1988). The $0.5-\mathrm{kg}$ CIST hammer may actually be the appropriate test device for 
determining the contribution of grass to surface hardness. Using the $0.5-\mathrm{kg}$ hammer, Bartlett et al. (2009) found that the measurement of surface hardness was affected by the mechanical properties of the grass, as well as the soil. In a study that compared 0.5and $2.25-\mathrm{kg}$ CIST hammers on grass leaf height treatments, it was shown that the initial drop of the $0.5-\mathrm{kg} \mathrm{CIST}$ hammer was more affected by the presence of grass and the third drop the 2.25-kg hammer was more sensitive to soil (Caple et al., 2011).

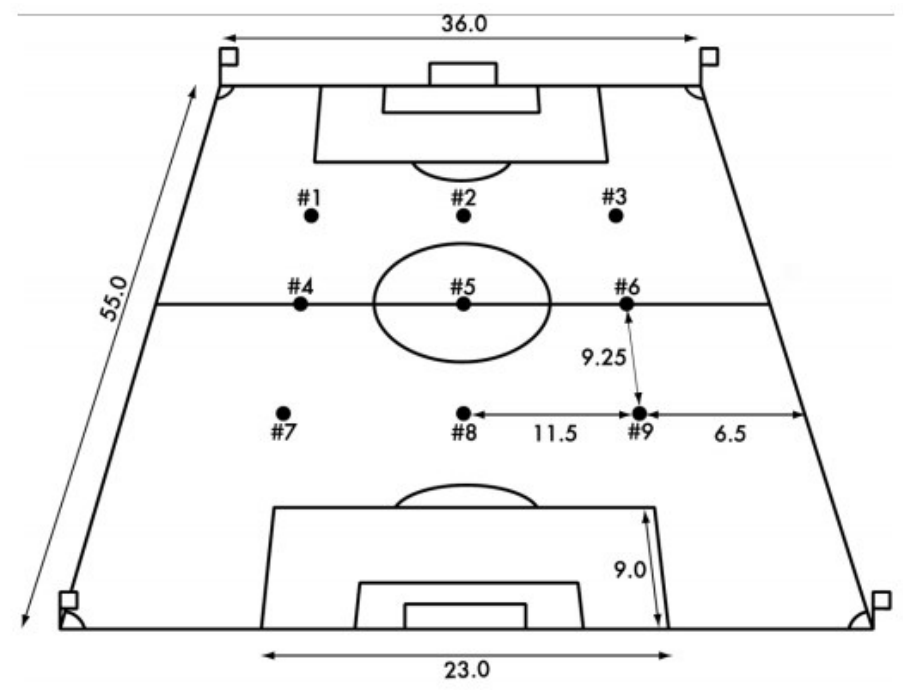

Fig. 1. Schematic of the youth soccer field showing the nine sampling locations for Fields $A$ and $B$. At each of the nine locations, two sets of measurements were taken no more than $0.5 \mathrm{~m}$ apart, one for green turfgrass and a separate one for brown turfgrass for a total of 18 measurements per field.

\section{Data Analysis}

Linear regression analysis was used for comparisons of soil VWC and surface hardness among areas of brown and green turfgrass. Analysis of covariance (ANCOVA) was used to evaluate whether the datasets from Fields $A$ and $B$ could be pooled for further analysis. Specifically, ANCOVA was used to compare both the slopes of the relationships between soil VWC and soil hardness, as well as the intercepts of the relationships. All statistical analysis was performed using R (R Core Team, 2012).

\section{Results and discussion}

The ANCOVA detected no significant differences in the relationship between soil VWC and soil hardness between Fields A and B (data not shown) with respect to both slope $(p>0.05)$ and intercept $(p>0.05)$, meaning that the data from the two fields could be 
pooled for further analysis. Soil VWC was roughly the same in the green turfgrass areas as it was in the brown areas of turfgrass (Fig. 2a).
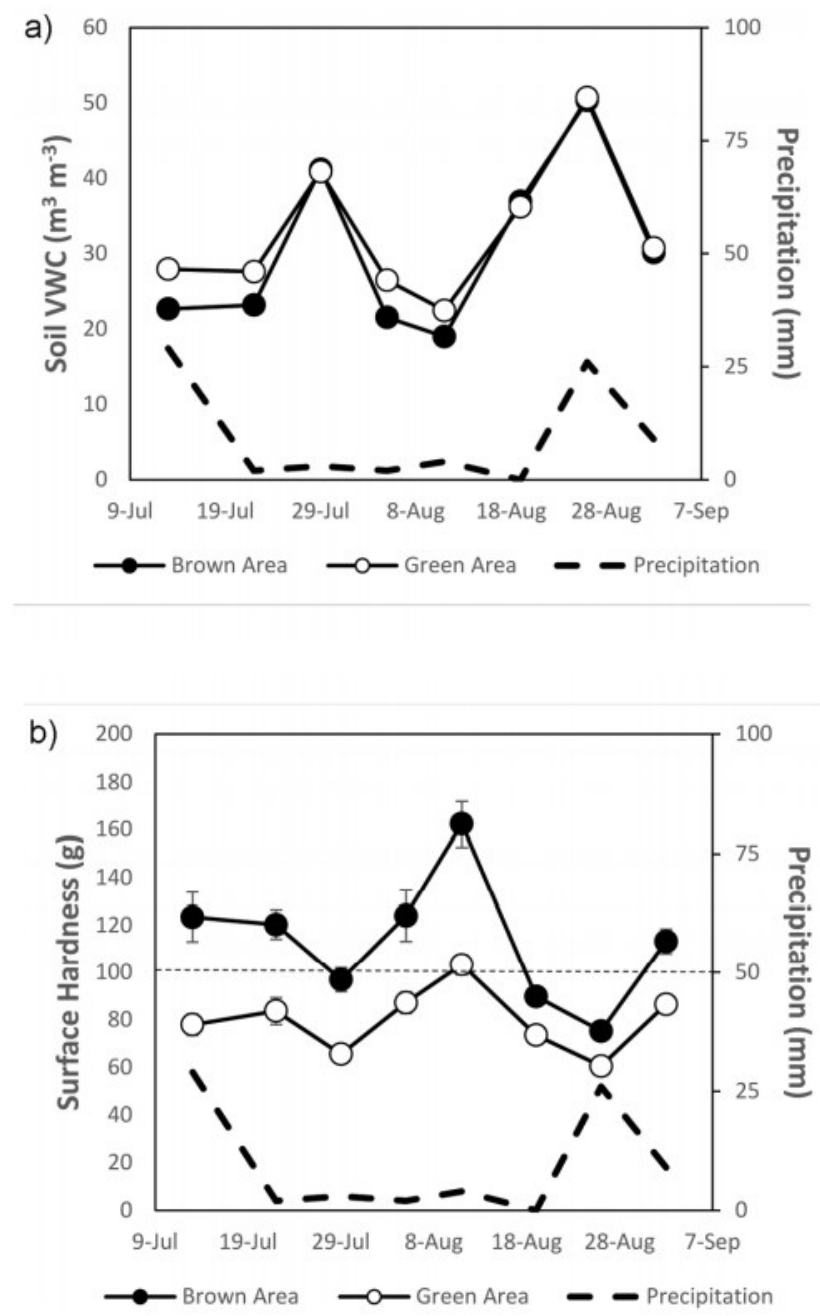

Fig. 2. Precipitation data summed every $7 \mathrm{~d}$ for days between sampling dates. (a) Mean soil volumetric water content (VWC, $\mathrm{n}=9$ per sampling date per field for green turfgrass areas and $n=9$ per sampling date per field for brown turfgrass areas). Although the error bars are present, they are too small to be seen on the figure. (b) Mean surface hardness measurements $(n=9$ per sampling date per field for green turfgrass areas and $n=9$ per sampling date per field for brown turfgrass areas). The line at $100 \mathrm{~g}$ represents the surface hardness threshold that may pose a safety hazard.

Linear regression analysis of soil VWC of green and brown areas indicated that the slope of the relationship was very close to one and almost identical over sampling dates (data not shown). Thus, it was unclear why some areas of turfgrass would be green and some areas with the same soil moisture would be brown. Visual inspection of the 
turfgrass at each location did not reveal any biotic reason (disease or insect pests) for the discoloration of the brown turfgrass, nor was there any difference in the relative composition of the plant species (Kentucky bluegrass, perennial ryegrass, and supina bluegrass) present. It is possible that there is a difference in the soil VWC between the green and brown turfgrass areas that was not discernable using the Theta probe. Perhaps most of the water was at a higher depth in the green turfgrass areas and at a lower depth in the brown turfgrass areas. This would create a scenario where water was more accessible to the plants in the green turfgrass areas, even though on average, both green and brown turfgrass areas had the same soil VWC. It was not possible to destructively measure biomass between the green and brown turfgrass, since the fields were being used.

Unlike soil VWC, surface hardness was not the same for green and brown turfgrass areas, with brown areas having consistently greater surface hardness, often $>100 \mathrm{~g}$, a value that may pose a safety risk for players (ASTM, 2010) (Fig. 2b). Linear regression analysis of the surface hardness of green and brown turfgrass areas across all sampling dates indicated that brown turfgrass areas were harder than areas of green turfgrass (data not shown).

Precipitation did affect field characteristics, especially later in the season when soil VWC increased and surface hardness decreased after a rainfall (Fig. 2a and 2b).

Whereas soil hardness decreased with increased soil VWC among all sites in the study, the green turfgrass areas were softer at a given soil VWC than brown turfgrass areas (Fig. 3). The effect was particularly prominent at soil VWC $<25 \mathrm{~m}^{3} \mathrm{~m}^{-3}$ and diminished as soil VWC increased.

The maintenance of turfgrass biomass on fields is known to moderate surface hardness and diminish injury risk (Rogers et al., 1988; Sifers and Beard, 1997; Ford and Twomey, 2016). Given these findings, not only is ground cover necessary, the maintenance of a green turfgrass cover is important for providing a cushioning effect on a sports field.

Although we did not measure the bulk density of the soil, it is plausible that soil within the areas of brown turfgrass may have been more compact than the green turfgrass 
areas. After a rain, water was observed to be puddling in the areas of brown turfgrass and not the areas of green turfgrass. Compaction is known to increase soil density, which in turn results in water runoff (Carrow, 1980). Vanini et al. (2007) have also noted the puddling of water in areas of high traffic, which the authors attributed to a more compacted surface. Surface hardness is affected to a greater degree by soil bulk density than by water content (McNitt and Landschoot, 2003). Additionally, soil water content has little effect on the surface hardness of sand-dominated rootzones, but for finer textured soil, water content is the major controlling factor of surface hardness (Rogers et al., 1988; Baker, 1991). The rootzone for the fields in this study was a sandy loam ( $>50 \%$ sand), so we would expect that the effect of soil water content on surface hardness would be reduced.

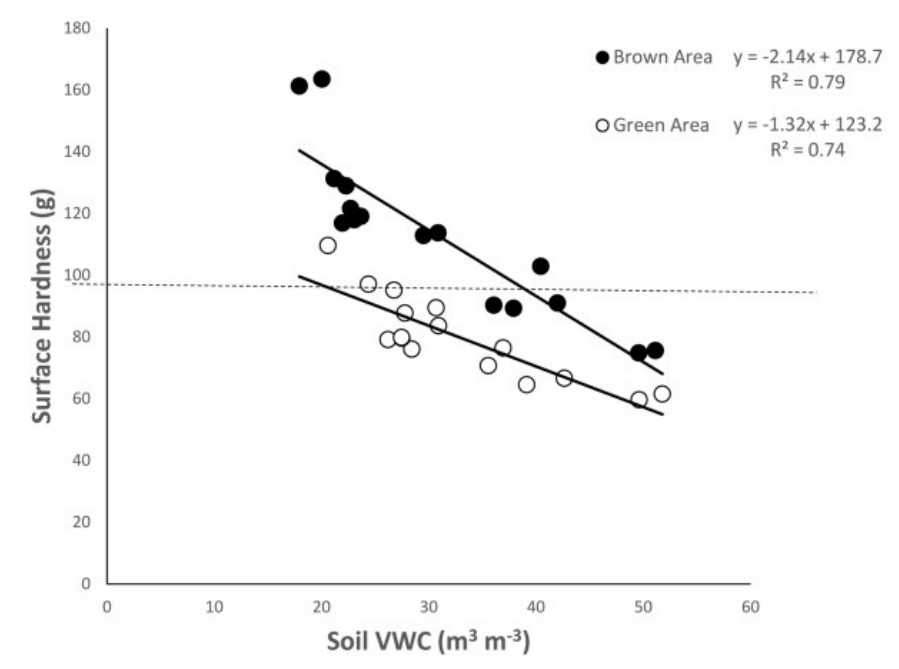

Fig. 3. The effect of soil volumetric water content (VWC) on surface hardness in green and brown turfgrass areas in close proximity $(n=9$ per field for green areas and $n=9$ per sampling date per field for brown areas) on each sampling date. The line at $100 \mathrm{~g}$ represents the surface hardness threshold that may pose a safety hazard.

Although soil bulk density may have been a contributing factor, we propose that the cushioning effect of green turfgrass verdure was the main factor in the measurable differences in surface hardness observed between areas of green and brown turfgrass. This underscores the importance of plant health maintenance through irrigation during times of low precipitation on natural turfgrass sports fields. 


\section{Conclusions}

The maintenance of natural turfgrass sports fields is a player safety issue. Irrigation of sports fields during times of limited precipitation is needed to preserve the cushioning effect of green turfgrass cover and minimize surface hardness. This would serve to decrease the risk of player injury, as well as to prevent plant death and the inherent costs of replanting.

\section{Conflict of Interest}

The authors declare that there is no conflict of interest.

\section{References}

ASTM. 2010. ASTM Standard F1702: Standard test method for measuring impactattenuation of natural playing surface systems using a lightweight portable apparatus. ASTM Int., West Conshohocken, PA.

Baker, S.W. 1991. Temporal variation of selected mechanical properties of natural turf football pitches. J. Sports Turf Res. Inst. 67:83-92.

Baker, S.W., and P.M. Canaway. 1993. Concepts of playing quality: Criteria and measurement. Int. Turfgrass Soc. Res. J. 7:172-181.

Bartlett, M.D., I.T. James, M. Ford, and M. Jennings-Temple. 2009. Testing natural sports surfaces: The value of performance quality standards. Proc. Inst. Mech. Eng., Part P: Sports Eng. Technol. 223:21-29.

Canaway, P.M., and S.W. Baker. 1993. Soil and turf properties governing playing quality. J. Sports Turf Res. Inst. 7:192-200.

Canaway, P.M., M.J. Bell, G. Holmes, and S.W. Baker. 1990. Standards for the playing quality of natural turf for association football. In: R.C. Schmidt, E.F. Hoerner, E.M. Milner, and C.A. Morehouse, editors, Natural and artificial playing fields: Characteristics and safety features. STP 1073. ASTM, Philadelphia, PA. p. 2947. doi:10.1520/STP25347S

Caple, M.C., I.T. James, and M.D. Bartlett. 2011. The effect of grass leaf height on the impact behaviour of natural turf sports field surfaces. Sports Technol. 4:29-40. doi:10.1080/1934618 2.2012.663537

Carrow, R.N. 1980. Influence of soil compaction on 3 turfgrass species. Agron. J. 72:1038-1042. doi:10.2134/agronj1980.000 21962007200060041x

Chivers, I., and D. Aldous. 2004. Performance monitoring of grassed playing surfaces for Australian rules soccer. J. Turfgrass Sports Surface Sci. 70:73-80. 
Chivers, I.H., D.E. Aldous, and J. Orchard. 2005. The relationship of Australian football grass surfaces to anterior cruciate ligament injury. Int. Turfgrass Soc. Res. J. 10:327-332. City of Guelph. 2016. City moves to outside water use level 2 red.

City of Guelph. http://guelph.ca/2016/07/city-movesoutside-water-use-level-2-red/ (accessed on 26 Sept. 2016).

Dixon, S.J., I.T. James, D.W. Blackburn, N. Pettican, and D. Low. 2008. Influence of footwear and soil density on loading within the shoe and soil surface during running. Proc. Inst. Mech. Eng., Part P: Sports Eng. Technol. 222:1-10.

Ford, P.G., and D.M. Twomey. 2016. Moderating surface hardness and rotational traction of natural turf communitylevel football fields in drought. Acta Hortic. 1122:111-120. doi:10.17660/ActaHortic.2016.1122.15

Gessel, L.M., S.K. Fields, C.L. Collins, R.W. Dick, and R.D. Comstock. 2007. Concussions among United States high school and collegiate athletes. J. Athl. Train. 42:495-503.

Hejduk, S., S.W. Baker, and C.A. Spring. 2012. Evaluation of the effects of incorporation rate and depth of water-retentive amendment materials in sports turf constructions. Acta Agric. Scand., Sect. B 62:155-164.

Low, D.C., and S.J. Dixon. 2014. Understanding the effect of changes to natural turf hardness on lower extremity loading. Meas. Control 47:212-218. doi:10.1177/0020294014546942

McNitt, A.S., and P.J. Landschoot. 2001. The effects of reinforcing inclusions in an athletic field rootzone. Int. Turfgrass Soc. Res. J. 9:565-572.

McNitt, A.S., and P.J. Landschoot. 2003. Effects of soil reinforcing materials on the surface hardness, soil bulk density, and water content of a sand root zone. Crop Sci. 43:957-966. doi:10.2135/cropsci2003.9570

Orchard, J. 2001. The AFL penetrometer study: Work in progress. J. Sci. Med. Sport 4:220-232. doi:10.1016/S1440- 2440(01)80032-3

Orchard, J. 2002. Is there a relationship between ground and climatic conditions and injuries in football? J. Sports Med. 32:419-432. doi:10.2165/00007256200232070-00002

Petrass, L.A., and D.A. Twomey. 2013. The relationship between ground conditions and injury: What level of evidence do we have? J. Sci. Med. Sport 16:105-112. doi:10.1016/j.jsams.2012.07.005

R Core Team. 2012. R: A language and environment for statistical computing. $R$ Foundation for Statistical Computing, Vienna, Austria.

Rennie, D.J., J. Vanrenterghem, M. Littlewood, and B. Drust. 2016. Can natural turf pitch be viewed as a risk factor for injury within association football? J. Sci. Med. Sport 19:547- 552. doi:10.1016/j.jsams.2015.07.009 
Rogers, J.N., III. 1988. Impact absorption and traction characteristics of turf and soil surfaces. Ph.D. diss., Pennsylvania State Univ., University Park, PA.

Rogers, J.N., III, and D.V. Waddington. 1990. Effects of management practices on impact absorption and shear resistance in natural turf. In: R.C. Schmidt, E.F. Hoerner, E.M. Milner, and C.A. Morehouse, editors, Natural and artificial playing fields: Characteristics and safety features. STP 1073. ASTM, Philadelphia, PA. $p$. 136-146. doi:10.1520/STP25357S

Rogers, J.N., III, D.V. Waddington, and J.C. Harper, II. 1988. Relationships between athletic field hardness and traction and vegetation, soil properties, and management practices. College of Agric., Agric. Exp. Stn. Prog. Rep. 393. Pennsylvania State Univ., University Park.

Sifers, S.I., and J.B. Beard. 1997. Enhancing participant safety in natural grass surfaces including the use of interlocking mesh element matrices. In: E.F. Hoerner, editor, Safety in American football. ASTM, West Conshohocken, PA. p. 156-166. doi:10.1520/STP11783S

Twomey, D.M., L. Otago, S. Ullah, and C.F. Finch. 2011. Reliability of equipment for measuring the ground hardness and traction. Proc. Inst. Mech. Eng., Part P: Sports Eng. Technol. 225:131-137.

Twomey, D.M., L.A. Petrass, J.W. Orchard, and C.F. Finch. 2014. Ground condition as a risk factor in sports aetiology studies: The level of concordance between objective and subjective measures. Injury Epidemiol. 1:27. doi:10.1186/s40621014-0027-y

Vanini, J.T., J.J. Henderson, J.C. Sorochan, and J.N. Rogers, III. 2007. Evaluating traffic stress by the Brinkman Traffic Simulator and the Cady Traffic Simulator on a Kentucky bluegrass stand. Crop Sci. 47:782-786.

doi:10.2135/cropsci2006.07.0500 